\title{
Does the Sphingosine 1-Phosphate Receptor-1 Provide a Better or Worse Prognostic Outcome for Breast Cancer Patients?
}

\author{
Nigel J. Pyne* and Susan Pyne \\ Strathclyde Institute of Pharmacy and Biomedical Sciences, University of Strathclyde, Glasgow, United Kingdom
}

Keywords: Sphingosine 1-phosphate, breast cancer, Sphingosine 1-phosphate receptor, sphingosine kinase, disease specific survival, cell growth, cell migration

\section{INTRODUCTION}

The bioactive lipid, sphingosine 1-phosphate (S1P) is formed by the sphingosine kinase-catalyzed phosphorylation of sphingosine. There are two isoforms of sphingosine kinase termed SphK1 and SphK2 that are encoded by different genes and which exhibit distinct sub-cellular localization and biochemical properties to regulate overlapping and non-overlapping biology (1). S1P is either degraded by S1P lyase to produce $(E)$-2-hexadecenal and phosphoethanolamine or reversibly dephosphorylated by S1P phosphatase to regenerate sphingosine (1). S1P can be exported from cells [through transporter proteins such as Spns2 (2), MFsd2b (3), and some ABC proteins (4)] to bind to a family of five S1P-specific $\mathrm{G}$ protein coupled receptors $\left(\mathrm{S}_{1} \mathrm{P}_{1-5}\right)(5)$. There is substantial evidence to suggest that S1P has a critical role in cancer. For example, the knockout of lymphatic endothelial Spns2 reduces pulmonary metastasis via a mechanism that involves induction of a lymphopenia and an increase in effector $\mathrm{T}$ cells and natural killer (NK) cells to enhance tumor cell killing in the lung (6). Other evidence supports a role for S1P in transformation, epithelial mesenchymal transition (EMT), invasiveness, cancer cell survival and replicative immortality, tumor neovascularisation, and the Warburg effect (7).

\section{ROLE OF S1P IN DEFINING BREAST CANCER PROGNOSIS}

Lei et al. (8) used data mining and the Kaplan-Meier plotter (http://kmplot.com/analysis/index. php? $\mathrm{p}=$ service\&cancer=breast) to establish relationships between messenger RNA levels (rather than protein) of SphK1, SphK2, sphingosine 1-phosphate receptor $1\left(\mathrm{~S}_{1} \mathrm{P}_{1}\right)$, or sphingosine 1phosphate receptor $2\left(\mathrm{~S}_{1} \mathrm{P}_{2}\right)$ and 10 year relapse free survival of non-classified breast cancer (BCA) patients. High SphK1 mRNA in tumors had no effect on 10 year relapse free disease survival, while high SphK2 mRNA was found to have a positive impact in patients with non-classified, or basal type $\mathrm{BCA}$ and those who had received adjuvant therapy. Lei et al. (8) also reported that high $\mathrm{S}_{1} \mathrm{P}_{1} \mathrm{mRNA}$ in tumors was associated with improved survival in patients with non-classified BCA and in those receiving treatment, but had no effect on patients with basal cell type BCA. In addition, improved survival was associated with high $\mathrm{S}_{1} \mathrm{P}_{2}$ mRNA in tumors from patients with non-classified BCA, basal cell type BCA and those patients receiving treatment.

We suggest that the interpretation of these findings should be viewed with considerable caution. In this regard, Kaplan-Meier plot analysis relating gene expression, i.e., mRNA transcript, with prognosis does not consider the possibility that mRNA transcript expression may not reflect specific protein levels. Indeed, it is the protein itself that performs the signaling function, and not the mRNA. In this regard, if the turnover of a particular protein is slow, its mRNA levels might be 
low. Therefore, a reciprocal relationship could exist between mRNA and protein levels. In this case, interpretation of the results by Lei et al. (8) would be completely reversed. For instance, it could be concluded that high expression of $\mathrm{S}_{1} \mathrm{P}_{1}$ protein (low mRNA transcript) in BCA tumors is linked with a poorer prognosis. Indeed, this was precisely the findings of Watson et al. (9) where the estrogen receptor positive $\left(\mathrm{ER}^{+}\right)$ breast cancer tumors of a population of 304 patients was analyzed. In this respect, high protein expression of $\mathrm{S}_{1} \mathrm{P}_{1}$ or SphK1 (detected using immunohistochemical staining with anti$\mathrm{S}_{1} \mathrm{P}_{1}$ antibody or anti-SphK1 antibody) in tumors was associated with earlier disease recurrence and reduced disease specific survival times. The difference for $\mathrm{S}_{1} \mathrm{P}_{1}$ is not trivial with mean disease recurrence and disease specific survival times being shortened by between 3 and 8 years, respectively.

In addition, a relationship with poor prognosis was evident for both membrane and cytoplasmic localized $\mathrm{S}_{1} \mathrm{P}_{1}$; the latter probably reflects receptors that have been endocytosed in response to S1P, and which are capable of persistent signaling (10). In contrast, combined high nuclear localized $\mathrm{S}_{1} \mathrm{P}_{2}$ and cSrc protein expression in tumors is associated with increased disease specific survival times (11). Indeed, a thorough analysis of the impact of S1P receptor sub-types on breast cancer prognosis should also consider sub-cellular localization and this can only be performed using analysis of protein with validated anti-S1P receptor antibodies. There is a very substantial body of evidence that demonstrates that $\mathrm{S}_{1} \mathrm{P}_{1}$ promotes tumorigenesis through, for example, enhanced cell survival, migration, and angiogensis (7). The role of $\mathrm{S}_{2} \mathrm{P}_{2}$ in cancer is more controversial with evidence that it can either promote or inhibit tumorigenesis $(12,13)$. To rationalize these findings, we have proposed that the positive and negative function of the $\mathrm{S}_{1} \mathrm{P}_{2}$ receptor in cancer might be dependent on its sub-cellular localization (14).

Patient stratification based on ER, progesterone receptor and HER2 status is also important. This is exemplified by the finding that high expression of SphK1 protein in tumors actually increases disease specific survival times in $\mathrm{ER}^{+} / \mathrm{HER} 2^{+}$patients. Indeed, high expression of SphK1 induces a desensitization/tolerance to HER2-mediated signaling in $\mathrm{ER}^{+} / \mathrm{HER} 2^{+}$breast cancer cells (15).

\section{S1P RECEPTOR-DEPENDENT MECHANISMS}

To provide a mechanistic explanation for the clinical findings, Lei et al. (8) reported the inhibition of colony formation by MCF-7 cells $\left(\mathrm{ER}^{+}\right)$or triple negative MDA-MB-231 cells in response to treatment with S1P $(4-10 \mu \mathrm{M})$ for 2 weeks. Using shRNA knockdown of either $\mathrm{S}_{1} \mathrm{P}_{1}$ or $\mathrm{S}_{1} \mathrm{P}_{2}$ in MCF-7 and MDA-MB-231 cells, the authors showed that the inhibitory effect of S1P on colony formation was enhanced in both cell types upon $\mathrm{S}_{1} \mathrm{P}_{2}$ knockdown whereas $\mathrm{S}_{1} \mathrm{P}_{1}$ knockdown reduced the effect in MDA-MB-231 cells and was without effect in MCF-7 cells. However, there was no evidence presented to indicate that the effect of S1P on colony formation actually reflects an inhibition of growth assessed by, for instance, cellcycle analysis. This is critically important in order to validate the conclusions, because $\mathrm{S} 1 \mathrm{P}$ stimulates migration via $\mathrm{S}_{3} \mathrm{P}_{3}$ (15) and $\mathrm{S}_{1} \mathrm{P}_{1}$ (16). In contrast, the $\mathrm{S}_{1} \mathrm{P}_{2}$ receptor has been linked with inhibition of cell migration (17). Therefore, the findings by Lei et al. (8) regarding the effect of shRNA knockdown of $\mathrm{S}_{2} \mathrm{P}_{2}$ are in fact consistent with a relief of the inhibitory constraint of $\mathrm{S}_{2} \mathrm{P}_{2}$ on the migration of MCF7 and MDA-MB-231 cells in response to added S1P. This would reduce colony formation by enhancing dispersal and thereby preventing colony residency. The knockdown of $\mathrm{S}_{1} \mathrm{P}_{1}$ in reducing the inhibitory effect of S1P on colony formation of MDA-MB-231 cells is consistent with ablation of the positive effect of $\mathrm{S}_{1} \mathrm{P}_{1}$ on migration, which would enhance colony formation/residency. Thus, colony formation (without more extensive cell cycle analysis and assessment of migration) does not provide confirmation that S1P inhibits tumorigenesis in vitro. The effect of treatment with S1P for 2 weeks on S1P receptor expression was also not examined by Lei et al. (8).

The major functional S1P receptor type in MCF-7 cells is, in fact, the $\mathrm{S}_{1} \mathrm{P}_{3}$ receptor which induces activation of the ERK$1 / 2$ pathway via transactivation of the EGF receptor to promote migration $(18,19) . \mathrm{S} \mathrm{P}_{3}$ expression/function was not analyzed by Lei et al. (8). Furthermore, the EGF receptor kinase is positively linked with tumorigenesis and this is a rationale for the use of EGF receptor kinase inhibitors for the treatment of cancer. Therefore, in contrast to the authors' conclusions, these prior published findings strongly implicate S1P in promoting breast cancer tumorigenesis via an EGF receptor-dependent mechanism. Finally, the study by Lei et al. (8) takes no account of the other responses that $\mathrm{S} 1 \mathrm{P}$ regulates through its receptors and which are of relevance to cancer, such as migration, angiogenesis and chemo-resistance.

\section{CONCLUSION}

We conclude that meaningful analysis of the impact of tumor S1P receptor sub-type expression on the survival of breast cancer patients requires analysis of actual protein levels and not mRNA. There is also a need to stratify patient cohorts to consider for instance, ER and HER2 expression. In addition, the effects of S1P on colony formation of MCF-7 and MDA-MB-231 cells requires analysis of cell cycle progression and migration with respect to the function of different S1P receptor sub-types. Moreover, a comprehensive analysis of the protein expression of all S1P receptors in the breast cancer cells studied and their individual biological functions should be interrogated. This is important as it is unknown whether, for instance, knockdown of $\mathrm{S}_{1} \mathrm{P}_{1}$ and/or $\mathrm{S}_{1} \mathrm{P}_{2}$ has an effect on the expression of the other S1P receptors and whether there is redundancy and/or divergent biological functions of these receptors. Indeed, this appears to be the case as evidenced by lack of effect of $\mathrm{S}_{1} \mathrm{P}_{1}$ knockdown in MCF7 cells, where ${\mathrm{S} 1 \mathrm{P}_{3}}_{3}$ may play a more prominent role. Finally, Lei et al. (8) conclude that breast cancer could be 
treated with $\mathrm{S}_{1} \mathrm{P}_{1}$ specific agonists, but provide no in vivo data to support this. In contrast, we argue that the weight of published evidence clearly suggests that such $\mathrm{S}_{1} \mathrm{P}_{1}$ specific agonists have the potential to reduce disease specific survival times for breast cancer patients which is counterproductive in terms of therapy.

\section{REFERENCES}

1. Pyne S, Adams DR, Pyne NJ. Sphingosine 1-phosphate and sphingosine kinases in health and disease: recent advances. Prog Lipid Res. (2016) 62:93106. doi: 10.1016/j.plipres.2016.03.001

2. Hisano Y, Kobayashi N, Yamaguchi A, Nishi T. Mouse SPNS2 functions as a sphingosine-1-phosphate transporter in vascular endothelial cells. PLoS ONE (2012) 7:e3894. doi: 10.1371/journal.pone.0038941

3. Vu TM, Ishizu AN, Foo JC, Toh XR, Zhang F, Whee DM, et al. Mfsd2b is essential for the sphingosine-1-phosphate export in erythrocytes and platelets. Nature (2017) 550:524-8. doi: 10.1038/nature24053

4. Kobayashi N, Kobayashi N, Yamaguchi A, Nishi T. Characterization of the ATP dependent sphingosine 1-phosphate transporter in rat erythrocytes. J Biol Chem. (2009) 284:21192-200. doi: 10.1074/jbc.M109.006163

5. Blaho VA, Hla T. An update on the biology of sphingosine 1-phosphate receptors. J Lipid Res. (2014) 55:1596-608. doi: 10.1194/jlr.R046300

6. Weyden LV, Arends MJ, Campbell AD, Bald T, Wardle-Jones H, Griggs N, et al. Genome-wide in vivo screen identifies novel host regulators of metastatic colonisation. Nature (2017) 541:233-6. doi: 10.1038/nature20792

7. Pyne NJ, Pyne S. Sphingosine 1-phosphate and cancer. Nat Rev Cancer (2010) 10:489-503. doi: 10.1038/nrc2875

8. Lei FJ, Cheng BH, Liao PY, Wang HC, Chang WC, Lai HC, et al. Survival benefit of sphingosin-1-phosphate and receptors expressions in breast cancer patients. Cancer Med. (2018) 7:3743-54. doi: 10.1002/cam4.1609

9. Watson C, Long JS, Orange C, Tannahill CL, Mallon E, McGlynn LM, et al. High expression of sphingosine 1-phosphate receptors, S1P1 and S1P3, sphingosine kinase 1 , and extracellular signal-regulated kinase$1 / 2$ is associated with development of tamoxifen resistance in estrogen receptor-positive breast cancer patients. Am J Pathol. (2010) 177:2205-15. doi: 10.2353/ajpath.2010.100220

10. Pyne NJ, Pyne, S. Sphingosine 1-phosphate receptor 1 signalling in mammalian cells. Molecules (2017) 22:E344. doi: 10.3390/molecules22030344

11. Ohotski J, Edwards J, Elsberger B, Watson C, Orange C, Mallon E, et al. Identification of novel functional and spatial associations between sphingosine kinase 1, sphingosine 1-phosphate receptors and other signalling proteins that affect prognostic outcome in estrogen receptor-positive breast cancer. Int J Cancer (2013) 132:605-16. doi: 10.1002/ijc.27692

12. Lepley D, Paik JH, Hla T, Ferrer F. The G protein-coupled receptor S1P2 regulates Rho/Rho kinase pathway to inhibit tumor cell migration. Cancer Res. (2005) 65:3788-95. doi: 10.1158/0008-5472.CAN-04-2311

13. Ponnusamy S, Selvam SP, Mehrotra S, Kawamori T, Snider AJ, Obeid $\mathrm{LM}$, et al. Communication between host organism and cancer cells is

\section{AUTHOR CONTRIBUTIONS}

All authors listed have made a substantial, direct and intellectual contribution to the work, and approved it for publication.

transduced by systemic sphingosine kinase 1/sphingosine 1-phosphate signalling to regulate tumour metastasis. EMBO Mol Med. (2012) 4:761-75. doi: 10.1002/emmm.201200244

14. Ohotski J, Rosen H, Bittman R, Pyne S, Pyne NJ. Sphingosine kinase 2 prevents the nuclear translocation of sphingosine 1-phosphate receptor-2 and tyrosine 416 phosphorylated c-Src and increases estrogen receptor negative MDA-MB-231 breast cancer cell growth: the role of sphingosine 1-phosphate receptor-4. Cell Signal. (2014) 26:1040-7. doi: 10.1016/j.cellsig.2014. 01.023

15. Long JS, Edwards J, Watson C, Tovey S, Mair KM, Schiff R, et al. Sphingosine kinase 1 induces tolerance to human epidermal growth factor receptor 2 and prevents formation of a migratory phenotype in response to sphingosine 1phosphate in estrogen receptor-positive breast cancer cells. Mol Cell Biol. (2010) 30:3827-41. doi: 10.1128/MCB.01133-09

16. Waters CM, Long J, Gorshkova I, Fujiwara Y, Connell M, Belmonte KE, et al. Cell migration activated by platelet-derived growth factor receptor is blocked by an inverse agonist of the sphingosine 1-phosphate receptor-1. FASEB J. (2006) 20:509-11. doi: 10.1096/fj.05-4810fje

17. Sugimoto N, Takuwa N, Okamoto H, Sakurada S, Takuwa Y. Inhibitory and stimulatory regulation of Rac and cell motility by the G12/13-Rho and Gi pathways integrated downstream of a single $G$ protein-coupled sphingosine-1-phosphate receptor isoform. Mol Cell Biol. (2003) 23:1534-45. doi: 10.1128/MCB.23.5.1534-1545.2003

18. Sukocheva O, Wadham C, Holmes A, Albanese N, Verrier E, Feng F, et al. Estrogen transactivates EGFR via the sphingosine 1-phosphate receptor Edg-3: the role of sphingosine kinase-1. J Cell Biol. (2006) 173:301-10. doi: $10.1083 /$ jcb.200506033

19. Long JS, Fujiwara Y, Edwards J, Tannahill CL, Tigyi G, Pyne S, et al. Sphingosine 1-phosphate receptor 4 uses HER2 (ERBB2) to regulate extracellular signal regulated kinase-1/2 in MDA-MB-453 breast cancer cells. J Biol Chem. (2010) 285:35957-66. doi: 10.1074/jbc.M110.117945

Conflict of Interest Statement: The authors declare that the research was conducted in the absence of any commercial or financial relationships that could be construed as a potential conflict of interest.

Copyright (C) 2018 Pyne and Pyne. This is an open-access article distributed under the terms of the Creative Commons Attribution License (CC BY). The use, distribution or reproduction in other forums is permitted, provided the original author(s) and the copyright owner(s) are credited and that the original publication in this journal is cited, in accordance with accepted academic practice. No use, distribution or reproduction is permitted which does not comply with these terms. 